\title{
Extractive Spectrophotometric Determination of Ruthenium (III) Using 2-(5- Bromo-2-Oxoindolin- 3-Ylidene) Hydrazine Carbothioamide as an Analytical Reagent
}

\author{
Parinita Madan, Vasant Barhate \\ V. E. S. College of Arts, Science and Commerce, Sindhi Society, Chembur, Mumbai 400071, India
}

\begin{abstract}
A simple, rapid and sensitive spectrophotometric method has been developed for the determination of Ru(III) by using 2-( 5Bromo -2-Oxoindolin-3-ylidene)Hydrazine Carbothioamide or HBITSC as an analytical reagent HBITSC has been synthesized and characterized by elemental and spectral analysis. HBITSC extracts Ru(III) quantitatively (99.52 \%) into n-amyl alcohol from an aqueous solution of pH range 3.5-5.7 and in the presence of $3 \mathrm{~cm}^{3}$ of acetate buffer (pH 4.6) and $3 \mathrm{~cm}^{3}$ of $1 \mathrm{M} \mathrm{LiCl}$. The n-amyl alcohol

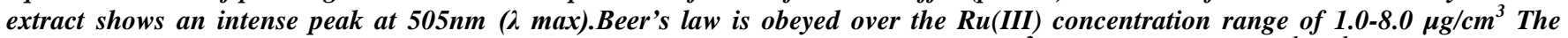
Sandell's sensitivity and molar absorptivity for Ru-HBITSC system is $10.25 \mathrm{ngcm}^{-2}$ and $9855.95 \mathrm{~L} \mathrm{~mole}$ cm $^{-1}$ respectively. The composition of extracted species is found to be 1:3 [Ru: HBITSC] by Job's Continuous Variation and Mole Ratio Method. Interference by various ions has been studied. The proposed method is rapid, sensitive, reproducible and has been successfully applied for determination of $\mathrm{Ru}(\mathrm{III})$ in alloy sample.
\end{abstract}

Keywords: Extractive Spectrophotometry, Ru(III), [ 2-(5-Bromo -2-Oxoindolin-3- ylidene)Hydrazine Carbothioamide[HBITSC] , Alloy Sample.

\section{Introduction}

Ruthenium is one of the rarest elements in the Earth's crust. Its abundance is estimated at about 0.0004 parts per million. Ruthenium together with rhodium, palladium, platinum, osmium and iridium forms a group of elements referred to as the platinum group metals (PGM). Ruthenium is the best hardeners for addition to palladium or platinum. Ruthenium compounds are highly toxic and are carcinogenic. Compounds of ruthenium stain the skin, eyes and respiratory tract (mouth, throat, and lungs) very strongly. Ruthenium is mainly used as alloys and as catalysts for industrial processes. Ruthenium-106 is used to treat certain forms of eye cancer.

A solvent extraction is becoming important separation technique in chemistry. During the past two decades, considerable attention has been paid to the chemistry of the Schiff bases containing nitrogen and other donor atoms and most of them are used as an efficient analytical reagent in trace analysis of some metal cations[1-21]

HBITSC has been used for the development of spectrophotometric method for determination of Palladium (II)[16] and Nickie(II)[17]. In the present communication, we describe the extractive spectrophotometric determination of $\mathrm{Ru}(\mathrm{III})$ withKeywords: Extractive Spectrophotometry,
Ru(III),[ 2-(5-Bromo -2-Oxoindolin- 3-ylidene)Hydrazine Carbothioamide or 5- Bromo Isatin thiosemicarbazone [HBITSC].

\section{Material and Methods}

All the used chemicals and solvents were of AR grade and were used without further purification and all the solutions were prepared in doubly distilled water.

ELICO - SL 159 spectrophotometer with optically matched quartz or glass cells of $1 \mathrm{~cm}$ path length were used for absorbance measurement. An ELICO LI-127 pH meter was employed for $\mathrm{pH}$ measurements.

Synthesis of ligand 2-(5-Bromo -2-Oxoindolin-3ylidene)Hydrazine Carbothioamide [HBITSC].

Schiff base ligand HBITSC was synthesized by refluxing equimolar amount of ethanolic solution of 5-Bromoisatin with thiosemicarbazide for 4 - 5 hours. On cooling the reaction mixture, a sharp yellow crystalline product separated out (80\%, yield) which was collected by filtration. The resulting HBITSC was recrystallised using aqueous ethanol as the procedure recommended by Vogel[19]. The product was characterized by elemental and spectral analysis. 


\section{International Journal of Science and Research (IJSR) \\ ISSN (Online): 2319-7064}

Index Copernicus Value (2013): 6.14 | Impact Factor (2015): 6.391

Its solution was prepared in Dimethylformamide (DMF). A stock solution of $\mathrm{Ru}$ (III) was prepared by dissolving accurately weighed ruthenium chloride in conc. hydrochloric acid by heating on a boiling water bath and the solution was then diluted to $250 \mathbf{c m}^{3}$ with double distilled water. Its solution was standardized by thiourea method[20]. Working solutions of Ru (III) were made by diluting the stock solution to an appropriate volume. All other reagents used were of AR grade and all the solutions were prepared in doubly distilled water.

\section{Extractive Spectrophotometric Determination of Ru(III)}

To an aliquot of aqueous solution containing $10-80 \mu \mathrm{g}$ of $\mathrm{Ru}(\mathrm{III}), 3 \mathrm{~cm}^{3}$ of acetate buffer solution of $\mathrm{pH} 4.6,3 \mathrm{~cm}^{3}$ of $1 \mathrm{M}$ $\mathrm{LiCl}$. and $1 \mathrm{~cm}^{3}$ of $1.0 \%$ solution of HBITSC prepared in DMF was added and solution was digested for 25 minutes in boiling water bath. A resulting solution was cooled to room temperature and then volume of solution was made up to 10 $\mathrm{cm}^{3}$ with distilled water and then equilibrated for $1 \mathrm{~min}$ with 10 $\mathrm{cm}^{3}$ of n-amyl alcohol and the phases were allowed to separate. The n-amyl alcohol extract was collected in a $10 \mathrm{~cm}^{3}$ measuring flask and made up to mark with n-amyl alcohol .The absorbance of n-amyl alcohol extract was measured at $505 \mathrm{~nm}$ against a reagent blank prepared under identical conditions. The Ruthenium content of the sample solution was determined from calibration curve. To study the effect of other ions, the respective foreign ions were added to aqueous phase before the extraction and adjustment of $\mathrm{pH}$.

\section{1) Determination of Ru (III) in Alloy Sample}

0.1 to 0.2 gm sample was dissolved in boiling with $10 \mathrm{ml}$ of aquaregia. The resulting solution was evaporated to dryness and the residue was then dissolved in $10 \mathrm{ml}$ of $1 \mathrm{~N} \mathrm{HCl}$ filter, if required and solution was diluted to $100 \mathrm{ml}$ with doubly distilled water. The working solution was prepared by appropriate dilution of stock solution. From an aliquot of this solution $1 \mathrm{ml}$ was analyzed for Ru (III) by the procedure as described earlier.

\section{Result and Discussion}

$\mathrm{Ru}(\mathrm{III})$ could be extracted quantitatively (99.52\%) by HBITSC into n-amyl alcohol from an aqueous solution of $\mathrm{pH}$ 3.5 to 5.7(Fig.1). Organic solvents used for extraction of $\mathrm{Ru}(\mathrm{III})$ can be arranged on the basis of their extraction coefficient values as n-amyl alcohol > n-butanol> ethyl acetate $>$ benzyl alcohol $>$ chloroform $>$ carbon tetrachloride $>$ xylene $>$ nitrobenzene $>$

toluene $>$ chlorobenzene(Fig.2). n-amyl alcohol was found to be the best extracting solvent; hence, it was selected for extraction throughout the work. The n-amyl alcohol extract of Ru - HBITSC complex showed intense peak at $505 \mathrm{~nm}$. (Fig.3). The absorbance due to the reagent is negligible at this wavelength, so the absorption measurements were taken at this wavelength. The result shows that the system confirmed to Beer's law at this wavelength over an Ruthenium concentration range 1.0 to $8.0 \mu \mathrm{g} / \mathrm{cm}^{3}$ (Fig.4). The molar absorptivity of the extracted complex on the basis of $\mathrm{Ru}(\mathrm{III})$ content was calculated to be $9855.95 \mathrm{~L} \mathrm{~mol}^{-1} \mathrm{~cm}^{-}$ ${ }^{1}$.The Sandell's sensitivity was found to be $10.25 \mathrm{ng} / \mathrm{cm}^{2}$. It was found that $1 \mathrm{~cm}^{3}$ of $1.0 \%$ DMF solution of HBITSC was sufficient to extract $80 \mu \mathrm{g}$ of $\mathrm{Ru}(\mathrm{III})$. The colour of the namyl alcohol extract was found to be stable at least 48 hrs at room temperature.

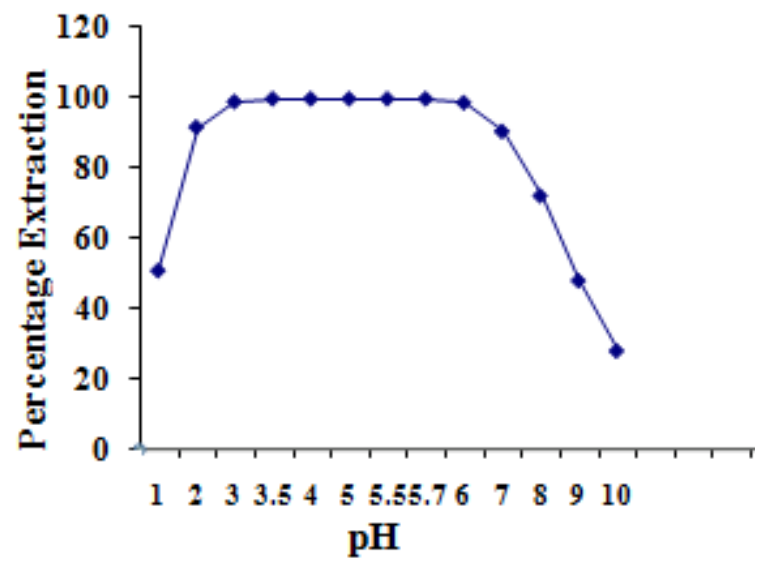

Figure 1: Effect of $\mathrm{pH}$ on the Extraction of $\mathrm{Ru}(\mathrm{III})$ with ligand 2-(5-Bromo -2-Oxoindolin-3-ylidene)Hydrazine Carbothioamide in n-amyl alcohol

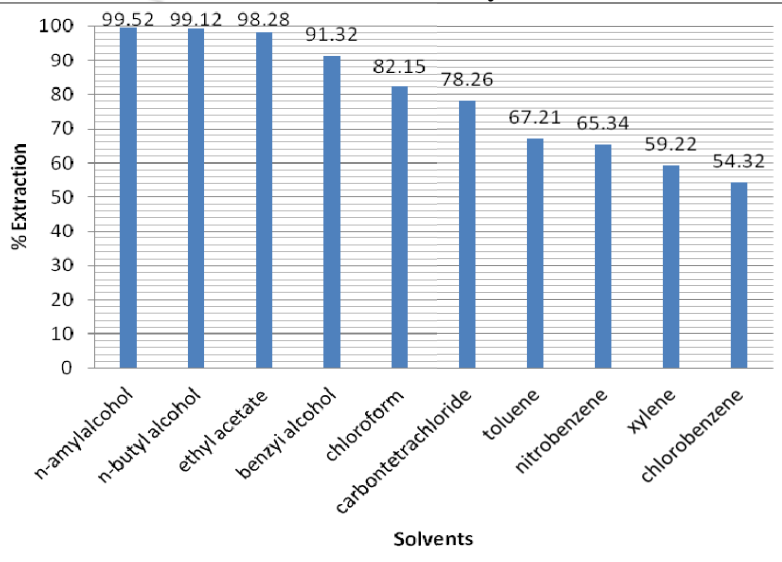

Figure 2: Percentage Extraction of Ru(III) into Various Organic Solvents

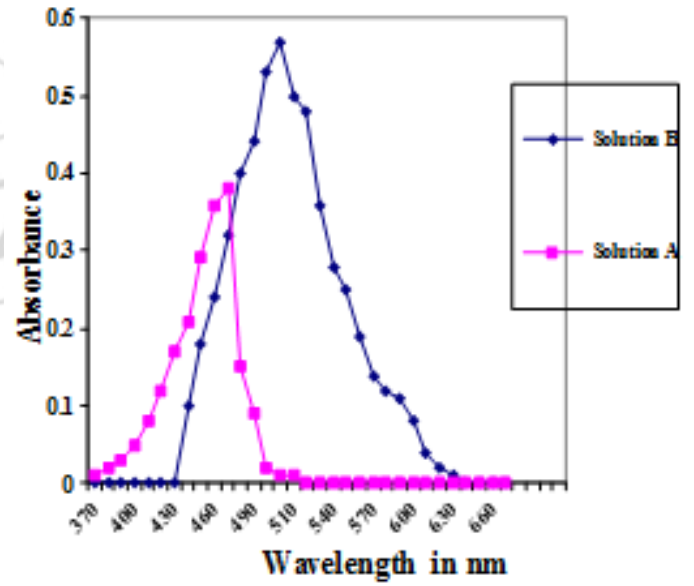

Figure 3: Solution A: Absorbance spectra of HBITSC, Solution B: Absorbance spectra of Ru- HBITSC Complex 


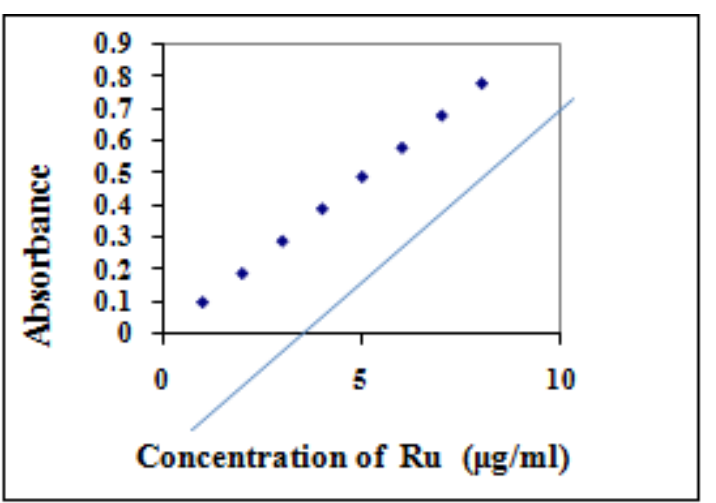

Figure 4: Calibration curve for Ru(III)

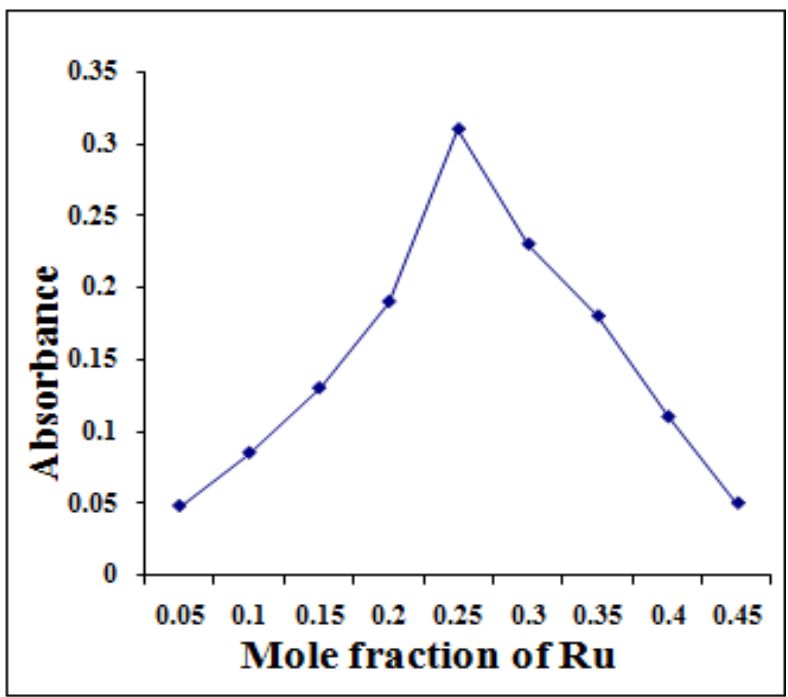

Figure 5: Composition of extractive species Ru:HBITSC by Job's Continuous variation method

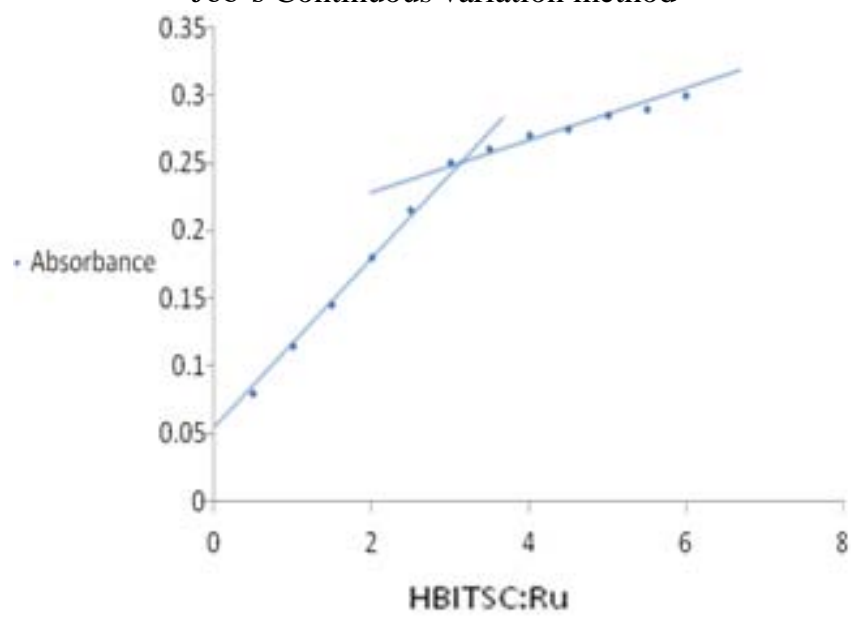

Figure 6: Composition of extractive species Ru:HBITSC by Mole Ratio Method

\section{Effect of other ions}

$\mathrm{Ru}(\mathrm{III})(40 \mu \mathrm{g})$ was determined in the presence of various ions. The following ions in the amount indicated, did not interfere in the spectrophotometric determination of $\mathrm{Ru}(\mathrm{III})$

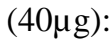
a) $10 \mathrm{mg}$ each of $\mathrm{Li}(\mathrm{I}), \mathrm{Ca}(\mathrm{II}), \mathrm{Mg}(\mathrm{II}), \mathrm{Al}(\mathrm{III}), \mathrm{Ba}(\mathrm{II})$, $\mathrm{Sr}(\mathrm{II}), \mathrm{Pb}(\mathrm{II}), \mathrm{Sn}(\mathrm{II}), \mathrm{Be}(\mathrm{II}), \mathrm{W}(\mathrm{VI}), \mathrm{Mo}(\mathrm{VI}), \mathrm{U}(\mathrm{VI})$ and $\mathrm{V}(\mathrm{V})$.
b) 5mg each of $\mathrm{Zn}(\mathrm{II}), \mathrm{Hg}(\mathrm{II}), \mathrm{Ag}(\mathrm{I})$, $\mathrm{As}(\mathrm{III}), \mathrm{Bi}(\mathrm{III})$ and $\mathrm{Sb}(\mathrm{III})$.
c) $2 \mathrm{mg}$ each of $\mathrm{Mn}(\mathrm{II})$ and $\mathrm{Cd}(\mathrm{II})$.

d) 1mg each of $\mathrm{Cr}(\mathrm{III}), \mathrm{Ce}(\mathrm{IV})$, $\mathrm{Th}(\mathrm{IV})$ and $\mathrm{Zr}(\mathrm{IV})$.

e) $0.5 \mathrm{mg}$ each of $\mathrm{Fe}(\mathrm{II}), \mathrm{Fe}(\mathrm{III})$ and $\mathrm{Ni}(\mathrm{II})$.

f) $0.1 \mathrm{mg}$ each of Co(II), Pt(IV), Os(IV), Ir(IV), Pd(II) and $\mathrm{Cu}(\mathrm{II})$.

g) $20 \mathrm{mg}$ each of - chloride, bromide, fluoride, sulphate, persulphate, nitrate, phosphate, acetate, oxalate, citrate and tartarate.

Interference due to iodide, nitrite and thiosulphate and EDTA was removed by boiling solution with concentrated $\mathrm{HNO}_{3}$ before the adjustment of $\mathrm{pH}$.

\section{Composition of the Extracted Complex:}

The composition of the extracted complex was found to be 1:3 (Ru:HBITSC) by Job's continuous variation and Mole ratio method (Fig.5 and Fig.6)

\section{Precision, Accuracy, Sensitivity and Application of} Method:

The precision and accuracy of the method were tested by analyzing the solution containing a known amount of $\mathrm{Ru}(\mathrm{III})$ following the recommended procedure. The average of 10 determination of $10 \mu \mathrm{g}$ of $\mathrm{Ru}(\mathrm{III})$ in $10 \mathrm{~cm}^{3}$ solutions was $10 . .45 \mu \mathrm{g}$, which is varied between $10.137 \mu \mathrm{g}$ and $10.763 \mu \mathrm{g}$ at 95\% confidence limit and standard deviation was $\mathbf{0 . 4 3 8}$ The proposed method has been applied for the determination of $\mathrm{Ru}(\mathrm{III})$ in synthetic samples.

The results of the analysis of the samples were comparable with those obtained by thiourea method[20] for $\mathrm{Ru}(\mathrm{III})$ (Table-1).

Table 1: Determination of Ru(III) in alloy sample

\begin{tabular}{|c|c|c|}
\hline Sample & $\begin{array}{c}\text { Ru (III) found (\%) } \\
* \text { Present method }\end{array}$ & $\begin{array}{c}\text { Ru (III) found (\%) } \\
\text { thiourea method }\end{array}$ \\
\hline Titanium Alloy & 0.099 & 0.100 \\
\hline
\end{tabular}

(*Average of three determinations)

\section{Acknowledgement}

Authors are thankful to the Principal Dr. (Mrs.) J.K.Phadnis, V.E.S. College of Arts, Science and Commerce, Sindhi Society, Chembur, Mumbai -71 for providing necessary research facilities.

\section{References}

[1] Shirodkar SG, Mane PS, Chondhekar TK, Synthesis and fungitoxic studies of $\mathrm{Mn}(\mathrm{II}), \mathrm{Co}(\mathrm{II}) \cdot \mathrm{Ni}(\mathrm{II})$ and $\mathrm{Cu}(\mathrm{II})$ with some hetrocyylic Schiff base ligands, Indian j. Chem,2001; 40: 1114-1117.

[2] Shelar SY, Bhor RJ, Anuse MA, Naval RM, Separation and Spectrophotometric Determination of Osmium(IV) and Ruthenium(III) with O-methoxyphenyl Thiourea as Chromogenic Legand: Sequential Separation of Osmium(IV), Ruthenium(III), and Platinum(IV) and Platinum(IV), Separation Science and Technology. 2015; 50: 1190-1191.

[3] Makhijani R M, Barhate V D, Extractive Spectrophotometric Determination of Ruthenium (II) With [N-(O-Methoxy Benzaldehyde) -2 - Amino Phenol], International Journal of ChemTech Research. 2013; 5: 1578-1584.

\section{Volume 5 Issue 4, April 2016}




\section{International Journal of Science and Research (IJSR) \\ ISSN (Online): 2319-7064}

Index Copernicus Value (2013): 6.14 | Impact Factor (2015): 6.391

[4] Sawant S Extractive Separation and Spectrophotometric Determination of Traces of Ruthenium from Mixtures Containing Excess Platinum Group Metals, Analytical Letters.2009; 42: 1678-1692

[5] Mathew B, Mini V, Vinnifred A, Microquantitative determination of ruthenium(III) spectrophotometrically using a schiff's base derived from a triazine, Pelagia Research Library.2010;1:7-14.

[6] Balcerzak M, Wyrzykowska E, Extraction preconcentration of platinum and ruthenium using high molecular weight amines prior to simultaneous determination by derivative spectrophotometry, Analusis.1999;27:829-834.

[7] Dru\{kovi\} V, Vojkovi V, Antoni T,Extraction of Ruthenium and Its Separation from Rhodium and Palladium with 4-Pyridone Derivatives, Croatica Chemica Acta.2005;78:617-626.

[8] Zeng L, Yu Chen, Jiangping L, Huang H, Guan R, Chao $\mathrm{H}$, Ruthenium(II) Complexes with 2Phenylimidazo[4,5][1,10]phenanthroline Derivatives that Strongly Combat Cisplatin-Resistant Tumor Cells, Scientific Reports.2016; 6:

[9] Vidhate K N, Gadekar L S, Lande M K, Arbad B R, Extractive spectrophotometric determination of ruthenium(III) with 4-(benzylideneimino)-5-methyl-4H1,2,4 -triazole-3-thiol, J. Indian Chem. Soc.2009;86:109112.

[10] Dolphin D, James B R, Murray A J, Thornback J R, Synthetic and oxidation studies of ruthenium(II) phthalocyanine complexes, CAN. J. CHEM. 1980;58:1125.

[11] Sinha P P, Tomer SKS, Asthana A, spectrophotometric determination of ruthenium present in traces, International Journal of Research in Engineering and Technology.2015;4:

[12] Gupta A S, Barhate V D, extractive spectrophotometric determination of ruthenium (iii) using [ $\mathrm{n}$ - (o - hydroxy benzylidene) pyridine - 2 - amine] (nohbpa) as an analytical reagent,Int. J. Chem. SC. 2011;9:1878-1884.

[13] Sharma A.R, Gangrade, Bakshi D, John J S, Ruthenium Complexes: - Potential candidate for Anti-Tumour Activity, International Journal of ChemTech Research.2014;6:828-837.

[14] Shanker K, Rohini R , Reddy P M, Ravinder V, Tetraaza Macrocyclic Ruthenium (II) Complexes: Synthesis Spectral and Catalytic Studies, International Journal of ChemTech Research.2009;1:300-307

[15] Rao R M, Chandrasekhar A , Devanna N, Determination of ruthenium(III) in the presence of micellar medium by derivative spectrophotometric technique, International Journal of ChemTech Research.2012;

[16] Madan PU, Barhate VD, Extractive Spectrophotometric Determination Of Palladium (II) Using 2-(5- Bromo-2Oxoindolin-3-Ylidene) Hydrazine Carbothioamide As An Analytical Reagent, Journal of chemical and pharmaceutical research. 2015; 7: 1113-1116.

[17] Madan PU, Barhate VD, Extractive Spectrophotometric Determination Of Nickel (II) Using 2-(5- Bromo-2Oxoindolin-3-Ylidene) Hydrazine Carbothioamide As An Analytical Reagent, International Journal for pharmaceutical research scholars, 2016; 5: 1-3.
[18]Feig F, Chemistry of specific selective and sensitive Reactions: English (Ed.) By R.E. Oesper, Academic press, New York, 1949.

[19] Vogel AI, Practical Organic Chemistry: 5th Ed., London; Longman group limited: 1989,

[20] Scott WW, Standard methods of chemical Analysis: Von Nostrad company Inc: 1939.

[21] Sandell E, Colorimetric determination of Traces of Metals: 3rd Edition. Interscience Publishers, INC., New York \& Interscience Publishers, LTD, London, (1961).

\section{Author Profile}

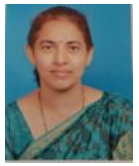

Parinita U. Madan has passed B.Sc. \& M.Sc. in the year April 1986 \& May 1988 respectively from Mumbai University. She is associate professor in VES College of Arts, Science \& Commerce. She has published 4 research papers in reputed research journals. She has also completed one research projects funded by UGC, New Delhi.

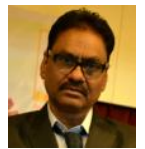

V. D. BARHATE: He has passed B.Sc. \& M.Sc. in the year April 1982 \& May 1984 respectively from Nagpur University. He has been awarded his Ph.D. in 1988 from Institute of Science, Mumbai University. He is associate professor in VES College of Arts, Science \& Commerce. He is recognized Ph.D. guide. He has guided 8 Ph.D. students \& 9 M.Sc. students. He has published 60 research papers in reputed research journals. He has also completed two research projects funded by Mumbai University \& UGC respectively. 